\title{
The route from problem to solution in multistep continuous flow synthesis of pharmaceutical compounds
}

\author{
Péter Bana ${ }^{\mathrm{a}}$, Róbert Örkényi ${ }^{\mathrm{a}}$, Klára Lövei ${ }^{\mathrm{b}}$, Ágnes Lakó ${ }^{\mathrm{a}}$, György István Túrós ${ }^{\mathrm{b}}$, János Éles ${ }^{\mathrm{b}}$, Ferenc Faigl ${ }^{\mathrm{a}, \mathrm{c}}$, \\ István Greiner ${ }^{\mathrm{b}, *}$ \\ a Department of Organic Chemistry and Technology, Budapest University of Technology and Economics, H-1521 Budapest, Hungary \\ ${ }^{\mathrm{b}}$ Gedeon Richter Plc., Gyömröi út 19-21, H-1103 Budapest, Hungary \\ ' MTA-BME Organic Chemical Technology Research Group, Budafoki út 8, H-1111 Budapest, Hungary
}

\section{A R T I C L E I N F O}

\section{Article history:}

Received 2 November 2016

Revised 20 December 2016

Accepted 27 December 2016

Available online $\mathrm{xxxx}$

\section{Keywords:}

Continuous flow processing

Active pharmaceutical ingredient

Telescoping

Multistep flow synthesis

In-line analytics

Continuous purification

\begin{abstract}
A B S T R A C T
Recent advances in the field of continuous flow chemistry allow the multistep preparation of complex molecules such as APIs (Active Pharmaceutical Ingredients) in a telescoped manner. Numerous examples of laboratory-scale applications are described, which are pointing towards novel manufacturing processes of pharmaceutical compounds, in accordance with recent regulatory, economical and quality guidances. The chemical and technical knowledge gained during these studies is considerable; nevertheless, connecting several individual chemical transformations and the attached analytics and purification holds hidden traps. In this review, we summarize innovative solutions for these challenges, in order to benefit chemists aiming to exploit flow chemistry systems for the synthesis of biologically active molecules.
\end{abstract}

(c) 2016 Elsevier Ltd. All rights reserved.

\section{Introduction}

The introduction of continuous processing into the manufacturing of active pharmaceutical ingredients (APIs) is actively encouraged from regulatory agencies, ${ }^{1}$ and some of the first examples of FDA approved, industrial production campaigns have been recently made public. ${ }^{2}$ Furthermore, moving to continuous processes in API production is expected to be economically beneficial. $^{3,4}$ However, these efforts are highly knowledge intensive ${ }^{5}$ and putting them into practice is admittedly more difficult than in the case of batch processes. ${ }^{6}$

To date, both laboratory and industrial scale API synthesis is conducted using classical organic synthesis methodologies, consisting of a sophisticated toolbox of reaction apparatus, analytical and work-up/purification techniques (Fig. 1a). On the other hand, flow chemical tools also provide many possibilities, ${ }^{7,8}$ but their implementation into multistep processes requires the design of the system, reaction conditions, analytics, work-up and purification processes, while constantly keeping this goal in mind (Fig. 1b).

Our ongoing efforts in this field ${ }^{9}$ inspired us to summarize the difficulties concerning the integration of individually optimized

\footnotetext{
* Corresponding author.

E-mail address: i.greiner@richter.hu (I. Greiner).
}

chemical reactions into multistep systems, as well as common problems and their innovative solutions described in the recent literature $^{6-8,10-18}$ of API continuous flow synthesis, including analytics and purification methods.

\section{Synthetic challenges}

\subsection{Choosing appropriate solvents}

The outcome of the whole process and the ease of work-up and purification can be largely influenced by the careful selection or omission of solvents (Fig. 2).

Applying a single solvent during the whole sequence of transformations reduces solvent consumption as well as the need for evaporation.

By choosing DMF as solvent for the whole process for the synthesis of condensed benzothiazoles, the three steps could be continuously coupled. ${ }^{9}$ The C-N coupling step involved in the synthesis of Imatinib was conducted in aqueous-organic biphasic system to prevent precipitation of inorganic byproducts, while $N$, $\mathrm{N}$-dimethyloctanamide cosolvent ensured efficient mass transfer and high reaction rates. Additionally, solubility problems were prevented, as each of the reagents could be dissolved in either aqueous or organic phase. ${ }^{19}$ 
(a) Classical multistep batch synthesis

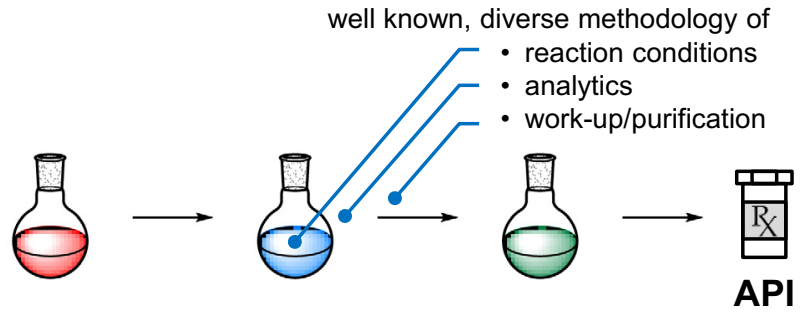

(b) Contiuous flow multistep system

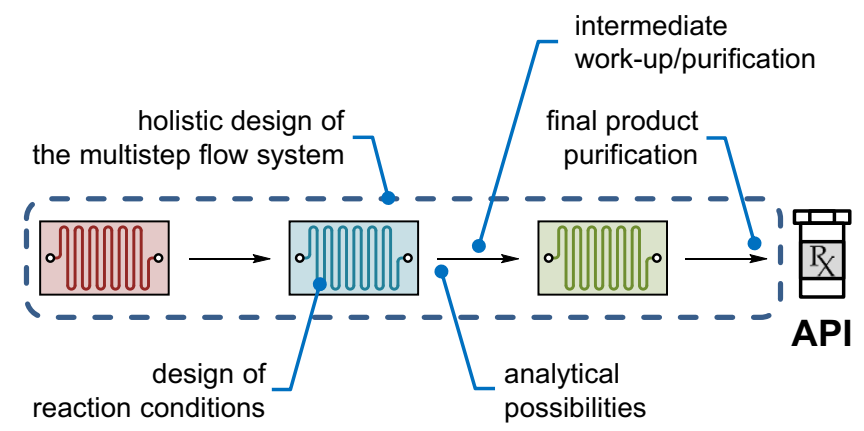

Fig. 1. Hidden traps in the realization of multistep flow synthesis of APIs.

Flow chemistry also enables working in solventless conditions. Neat or molten reagents led to higher reactivity and throughput in the multistep flow chemical preparation of Ibuprofen, ${ }^{20,21}$ Rufinamide, ${ }^{22}$ Aliskiren, ${ }^{23,24}$ Lidocaine and Diazepam. ${ }^{25}$

Complete removal of the solvent and introduction of a different one may be necessary in some cases, although only few continuous examples were described for such processes. During the synthesis of Oxomaritidine, the initially used THF had to be removed before the last steps. The crude intermediate was re-dissolved in DCM, which was also useful to avoid working with highly diluted mixtures in the final steps. ${ }^{26}$ THF was exchanged to acetonitrile using a nebulizing evaporator device to avoid polymerization side reaction under the acidic conditions of the next step in course of the synthesis of 2-aminoadamantane-2-carboxylic acid. ${ }^{27}$

Reactivity can be fine-tuned by slight modification of the solvent system by addition or removal of cosolvents. During the Olanzapine synthesis, addition of methanol to the hitherto employed ethyl acetate was necessary to obtain high yields in the cyclization step leading to a thieno[1,5]-benzodiazepine intermediate. ${ }^{28}$ On the contrary, the cosolvent had to be removed before the next step in the modular approach towards Pregabalin, Gabapentin and related drugs. The olefination step required small amounts of methanol in toluene to prevent precipitation of the intermediate phosphate salt, but methanol was not tolerated by the next Michael addition. Aqueous in-line work-up between the steps enabled the removal of the cosolvent. ${ }^{29}$

\subsection{The role of (pre)mixing}

Opposite to batch processing, where separately stored reagents are introduced sequentially, the compatibility of the components mixed together in the same stock solution and delivered by the same pump has to be considered.

Undesired reactions in the storage flask were prevented by introducing the base as a separate stream in a Buchwald-Hartwig amination in the first step of the flow synthesis of Olanzapine. ${ }^{28}$ In the synthesis of Lidocaine and Diazepam, separate pumps were used for the neat reagent and the solvent to avoid decomposition on standing. ${ }^{25}$

On the other hand, the preliminary deprotonation occurring in the premixed solution of the benzimidazole substrate and the base was found beneficial for reaching appropriate regio- and chemoselectivity in an alkylation leading to Telmisartan. ${ }^{30}$

When coupling the individually optimized steps during the synthesis of condensed benzothiazoles, significant differences were observed in the yields of the thiazole-formation step, depending on the premixing time. This problem was solved by adding reagents in two separate steps to the stream and inserting a coil reactor for mixing. ${ }^{9}$

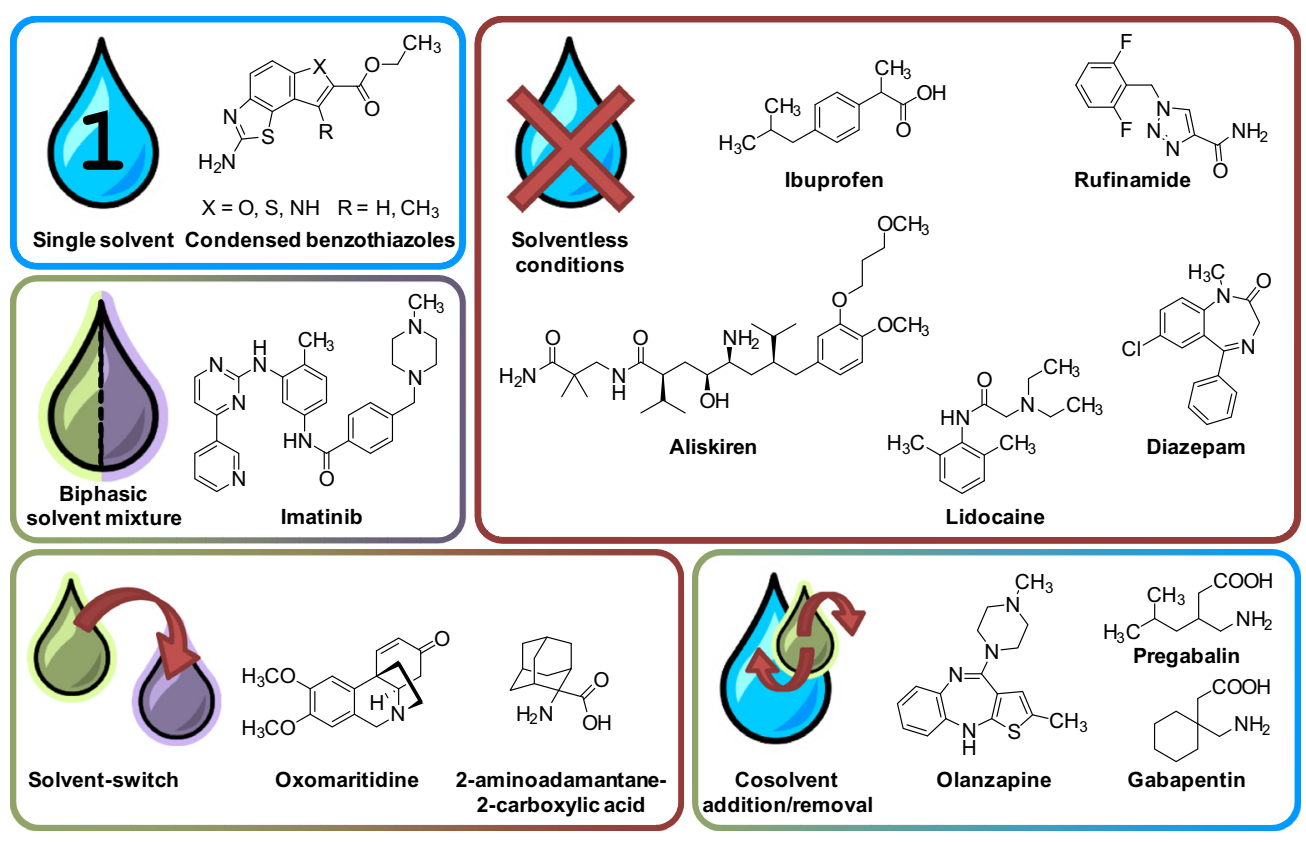

Fig. 2. Strategies for solvent selection in multistep flow systems for API synthesis. 


\subsection{Compatibility of reagents}

In complex systems, the interaction of sub-processes has to be taken into account during design.

Reagent systems were specifically engineered for best compatibility in Bogdan's approach to Ibuprofen (Fig. 12a). This enabled conducting three distinct chemical steps in an uninterrupted stream, while the excess of reagents and side products emerging from the previous steps were tolerated in downstream reactions. ${ }^{20}$

Highly selective reactions can tolerate the presence of chemically related impurities. In the Buchwald-Hartwig amination leading to Imatinib, excess of methyl piperazine (from the previous nucleophilic substitution) present in the reaction stream remained inert besides the aromatic amine coupling partner, if the BrettPhos ligand (which is selective towards primary amines) was used (Fig. 3). This way, removing excess reagent was unnecessary. ${ }^{19}$

A complex interplay of reagents had to be managed in the process to Rufinamide. The presence of ammonia (used in excess in the previous amidation) resulted in the pressure dependence of the copper catalyzed triazole synthesis, which required optimization (Fig. 4). While bubble formation due to outgassing of ammonia at lower pressures led to shorter residence times, at higher pressures the dissolved ammonia interfered with the activity of the copper catalyst by complex formation, causing lower yield. An optimum of 100 psi was found with minimal gas generation, while the catalyst remained active. ${ }^{31}$

\subsection{Simplification of the process}

Sophisticated synthetic procedures tend to get disproportionally complex. Nevertheless, extensive optimization allowed in flow chemistry equipment may lead to less complicated processes, which are chemically and technologically more feasible.

In the two-step synthesis of a Mur-ligase inhibitor, the condensation reaction generating imidazo bicycles was initially optimized in the presence of catalytic amounts of $p$-toluenesulfonic acid (PTSA). However, PTSA prevented the formation of the products in the following step. The simplification of the first step by omitting the acid catalyst solved this problem (Fig. 5). ${ }^{32}$

The proper design of the conditions helped avoiding a separate quenching step in the multistep synthesis of 2-aminoadamantane2 -carboxylic acid. The carbonyl oxide intermediate of the ozonolysis was decomposed in situ, in an acetone/water solvent system, thus the use of stoichiometric amounts of solid-supported thiourea reagent was avoidable. Furthermore, the hydrogen-peroxide formed as a by-product was catalytically decomposed on a manganese dioxide bed in the subsequent step. ${ }^{27}$

Optimization of the heterogeneous catalyst systems allowed a more straightforward process in the synthesis of $\gamma$-nitro malonates, which is closely related to the early synthetic steps of the flow preparation of Rolipram. ${ }^{33}$ In an earlier approach, the first step was conducted using nitromethane as a solvent (Fig. 6a). However, the excess of nitromethane had to be removed by distillation prior to the subsequent Michael addition of $\beta$-dicarbonyl compounds, to avoid byproduct formation by further addition of nitromethane to the $\beta$-nitrostyrene intermediate. ${ }^{34}$ Optimization of the catalyst and conditions of the first step eliminated the need for excess reagent (Fig. 6b), therefore the crude reaction mixture could be directly transferred to the next reactor without intermediate work-up. ${ }^{35}$

\subsection{Number of steps}

Multistep flow chemical sequences should be designed to employ the fewest number of chemical transformations, unit operations, reactors and pumping equipment, which helps minimizing the technical complexity of the system and its potential for errors and instabilities.

As shown in the synthesis of Iloperidone, chemical transformations requiring similar conditions can be conducted in a single reactor consecutively. This way, the ring closure and the $\mathrm{N}$-alkylation could be integrated after fine-tuning of the reaction conditions. $^{36}$

The efforts towards the synthesis of Daclatasvir employed an efficient chemical process for the formation of imidazole core structure. Instead of the laboriously synthesized $\alpha$-amido-ketones (Fig. 7a) used in the previous approach, ${ }^{37} \alpha$-acyloxy-ketones (Fig. 7b) were prepared in one step and transformed directly to the desired cyclic product. ${ }^{38}$

The number of pumps was courageously reduced by exploiting the convergent nature (Fig. 8) of the synthesis of Cinnarizine. Two transformations, conducted parallel in time, both requiring addition of $\mathrm{HCl}$, were carried out using a single pump. The stream was split prior to mixing with the substrates. The same concept was applied to the subsequent addition of $\mathrm{NaOH}$. Two parallel phase separations provided the chloro derivatives, of which diphenylmethyl chloride was reacted with excess piperazine to afford the monoalkylated intermediate. In the final step, two equivalents of cinnamyl chloride were employed to yield the desired API. ${ }^{39}$

It may occur, that increasing the number of steps is necessary, as shown in the reaction of phenols with epichlorohydrine towards Metoprolol and its derivatives. The base mediated alkylation (Fig. 9a) was split into two separate steps (Fig. 9b), in case the intermediate phenoxide was prone to precipitation. ${ }^{40}$

\subsection{Compatibility of flow rates}

Different types of chemical transformations can have inherently different throughputs (Fig. 10).

In the preparation of the key intermediate of Valsartan, the first part of the sequence required high flow rates to enable selectivity in the preparation of the boronate intermediate through lithium organic species. ${ }^{41}$ Then, the boronate was subjected to a Suzuki reaction using a monolithic palladium catalyst, which in turn, restricted the achievable flow rate. Reactor size could not be increased in this case; consequently, the high volumetric throughput boronate forming and the much slower flowing coupling sections of the system were connected by splitting the flow evenly to multiple streams by an elaborate flow distributor. ${ }^{42}$

\subsection{Reactor type matters}

The utilization of the proper type of microreactor ${ }^{43}$ can significantly affect the design and outcome of the reaction.

In an $\mathrm{N}$-oxidation reaction during the two-step preparation of $\mathrm{N}$-nordextromethorphan conducted in a glass column filled with sodium percarbonate, exothermic runaway leading to uncontrollable pressure expansion caused the column to shatter. To overcome this problem, a liquid-phase approach using $m$ chloroperbenzoic acid as oxidant was applied. The exotherm could be controlled due to the high surface area to volume ratio of the flow reactor. ${ }^{44}$

The structural elements of the reactor can also affect chemical transformations. Stainless steel tubing was replaced with commercial copper tubing to catalyze the [3+2] cycloaddition step in the synthesis of Rufinamide (Fig. 4). With this modification, both stereoselectivity and overall yields have improved. ${ }^{31}$

Tube-in-tube reactors based on the semipermeable Teflon ${ }^{\circledR}$ AF2400 tubing ${ }^{45,46}$ are suitable building blocks for multistep flow processes involving gaseous reagents (Fig. 11). Precise addition of gaseous $\mathrm{NH}_{3}$ using a tube-in-tube reactor allowed the two-step 


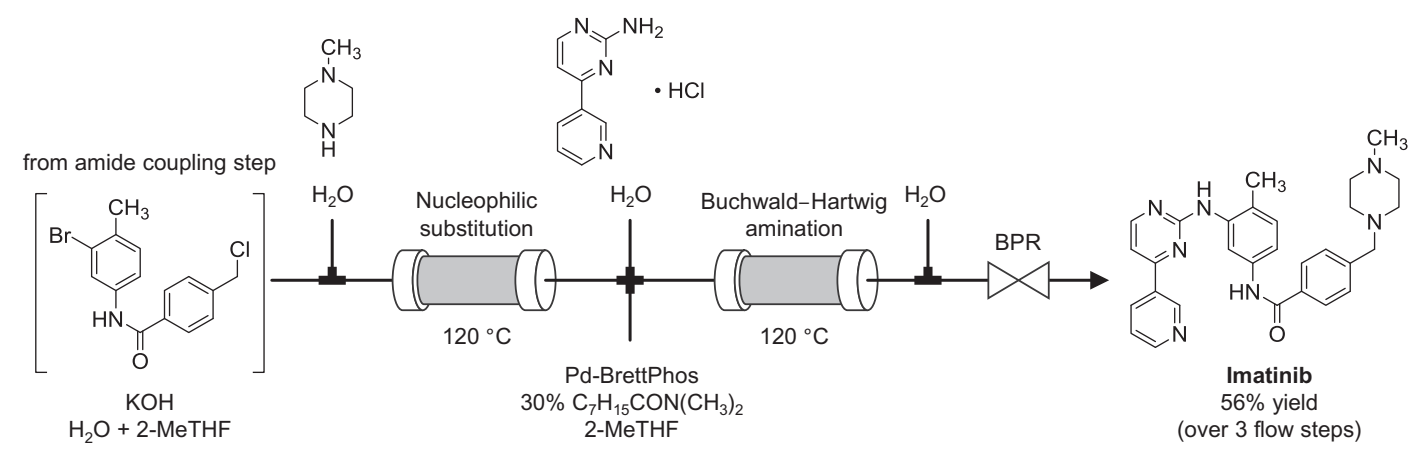

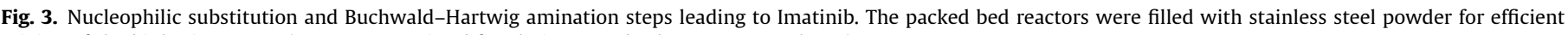
mixing of the biphasic stream. (Pumps are omitted for clarity, BPR: back pressure regulator.)

(a)

\section{from azide}

formation

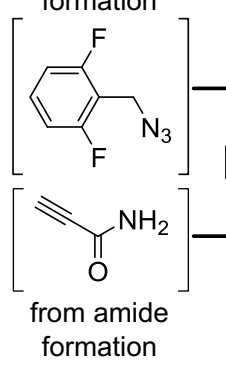

(b)

\section{yield of triazole}

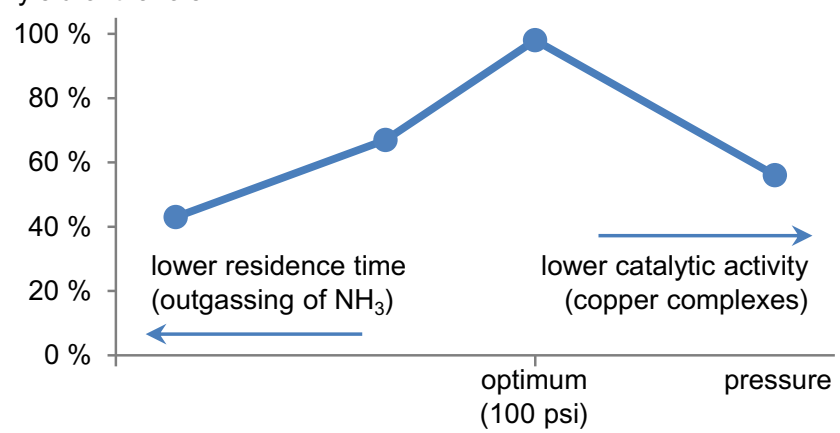

Fig. 4. (a) Final step of the synthesis of Rufinamide in a coil microreactor manufactured of copper tubing, (b) pressure dependence of the final step's yield. (Pumps are omitted for clarity, BPR: back pressure regulator.) uninterrupted flow synthesis of Fanetizole. ${ }^{47}$ Similarly, $\mathrm{CO}_{2}$ gas could be introduced into the stream of lithium organic intermediates, without compromising inert conditions during the continuous flow preparation of Amitriptyline. ${ }^{48}$

Hazardous gases can be generated in situ using the aqueous solutions of their precursors in a tube-in-tube device. The highly poisonous and explosive diazomethane could be safely used in the three-step flow process to $\alpha$-halo ketone building blocks of antiretroviral agents. The anhydrous reagent diffused through the gas permeable inner tube and immediately reacted with the substrate in the outer chamber. Any excess reagent was destroyed before leaving the closed system to prevent human exposure. ${ }^{49}$

Owing to scalability issues, photochemical and electrochemical transformations are rarely encountered in pharmaceutical manufacturing. However, miniaturization in continuous flow systems makes photo- ${ }^{50-53}$ and electrochemical ${ }^{54}$ reactors feasible. The synthetic pathways affordable in these systems can be involved in novel multistep flow processes leading to pharmaceutical compounds.

The convenient realization of a vital photochemical transformation in the semi-synthesis of Artemisinin related drugs was enabled by the continuous approach. ${ }^{55-57}$ Using a photochemical reactor, an unconventional route could be developed to Ibuprofen via a photo-Favorskii rearrangement. ${ }^{58}$

Continuous flow electrochemistry was used as an enabling technology in the synthesis of the indole alkaloid Nazlinine and its analogues. ${ }^{59}$ In an effort to simulate cytochrome P450 oxidation on a preparative scale, drug metabolites were produced by microfluidic electrosynthesis. Glutathione conjugates could be synthesized in a subsequent flow reactor, connected directly to the output of the electrochemical flow cell. ${ }^{60}$

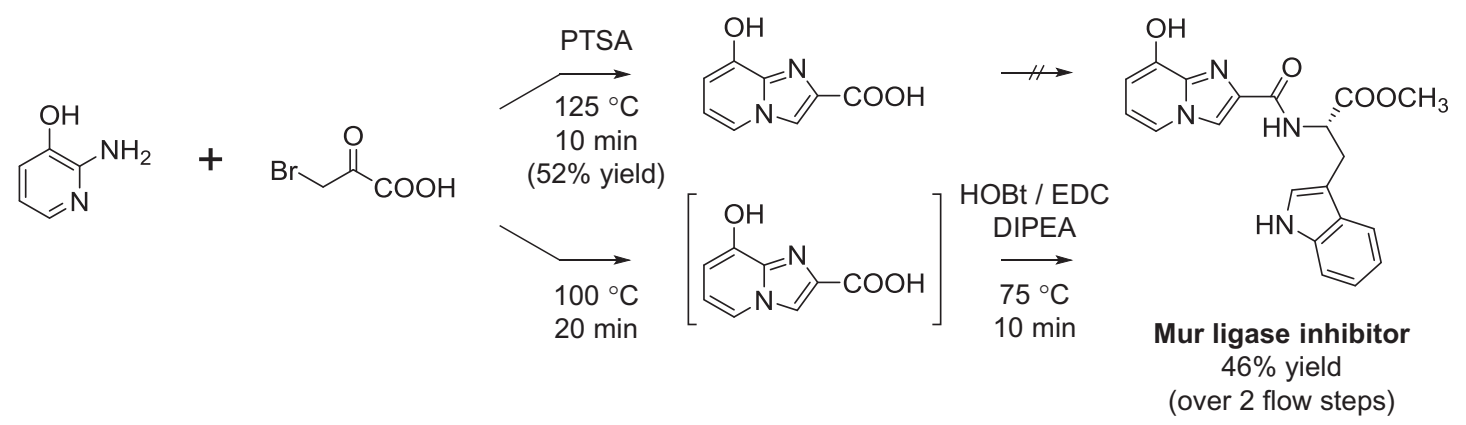

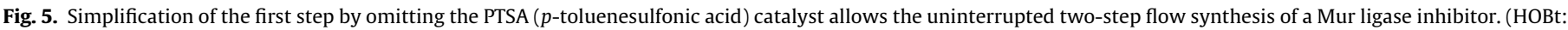
1-hydroxybenzotriazole, EDC: $N$-(3-dimethylaminopropyl)- $N$-ethylcarbodiimide, DIPEA: $N, N$-diisopropylethylamine). 


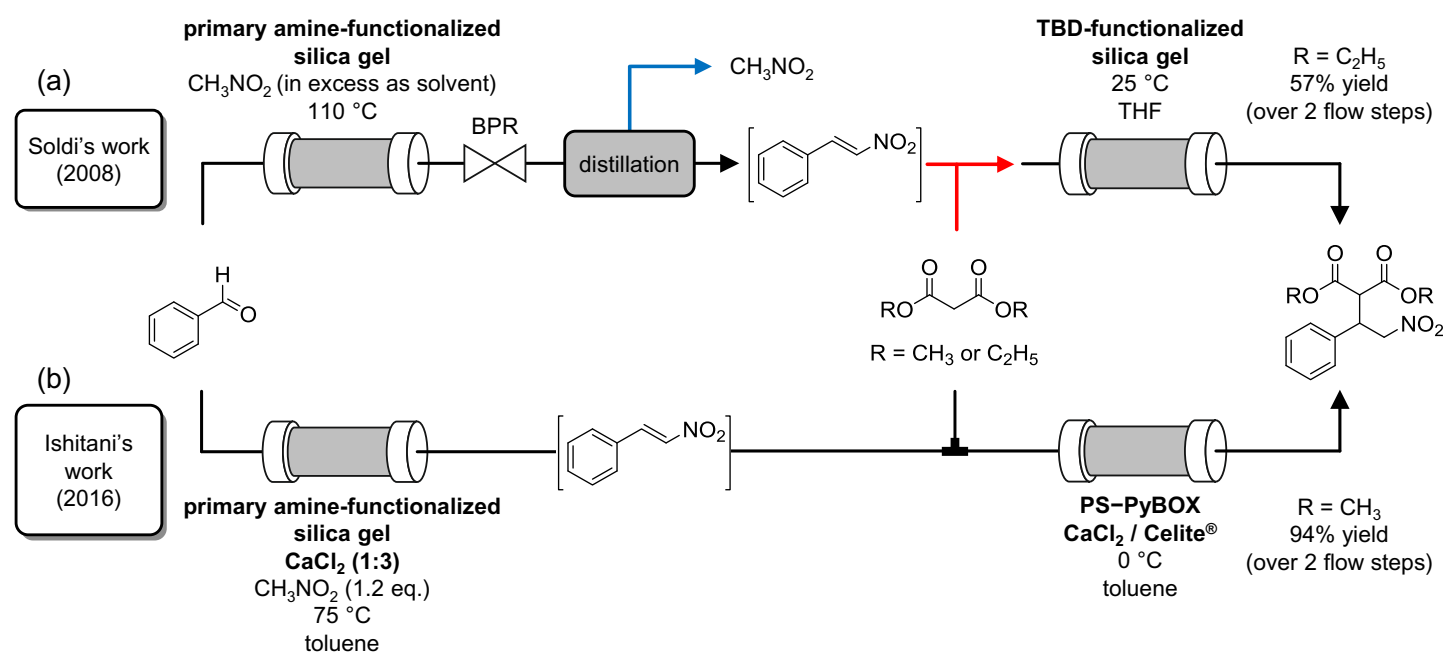

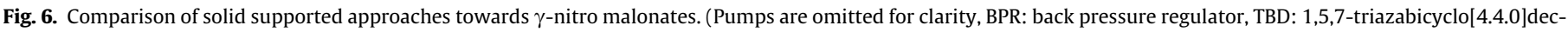
5-ene, PS-PyBOX: polymer supported pyridinebisoxazoline.)

(a)

$\alpha$-amido-ketone route

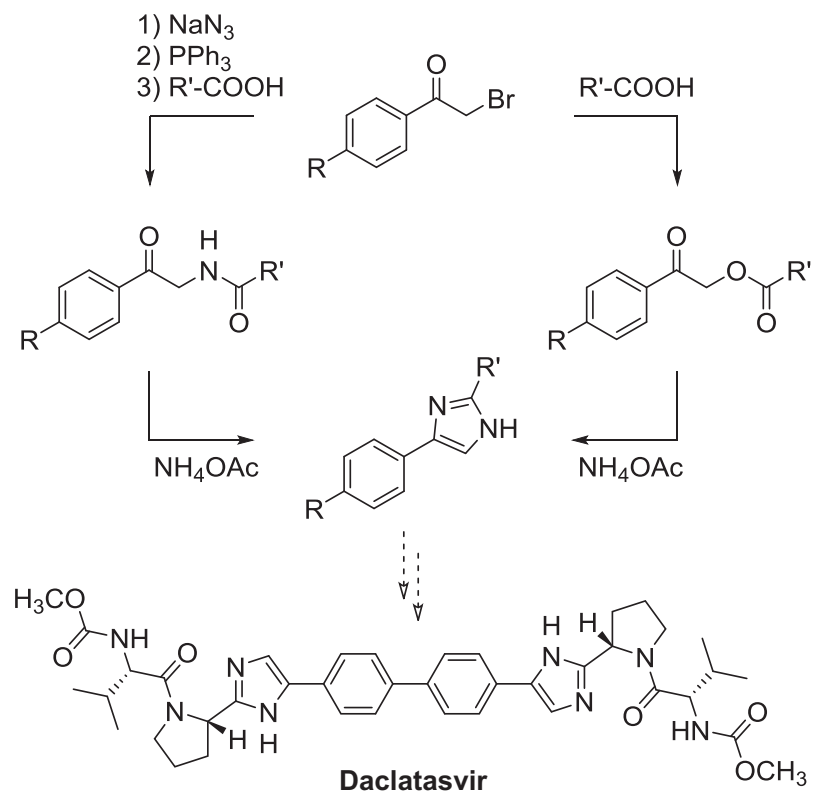

Fig. 7. Analysis of the possible routes for the preparation of imidazoles towards Daclatasvir.

\subsection{Better productivity}

Higher productivity for bulk APIs is obtainable by robust chemistries.

Compared to the first flow synthesis of Ibuprofen (Fig. 12a), designed for reagent compatibility, ${ }^{20}$ the authors of the more recent approach optimized the entire process to reach high throughput (Fig. 12b). Although the choice of the reagents led to high reactivity, the exothermic nature of the Friedel-Crafts reaction and its quenching had to be managed. Corrosivity and clogging issues could be mitigated by carefully choosing pumping and quenching methods. ${ }^{21}$

Another example of improved throughput was provided in the case of Imatinib. The first flow approach marked a milestone in multistep flow synthesis. This system enabled the preparation of various derivatives, but didn't permit large scale continuous production. ${ }^{61,62}$ Increased productivity was achieved in a subsequent study, by omitting solid supported reagents and intermediate inline purification steps in a system consisting of three continuously operated microreactors (Fig. 3). ${ }^{19}$

\subsection{Ensuring stability for continuous production}

Continuous flow processing can only be exploited for large scale production, if stable operation of the system can be ensured over longer periods of time, which is often hampered by corrosion and clogging.

Use of corrosive reagents can be prevented, by employing novel process windows available in flow equipment, which can also reduce the number of work-up operations. An elimination reaction, leading to Amitriptyline proceeded at high temperature without the use of previously employed concentrated $\mathrm{HCl}$ solution. ${ }^{48}$ On a similar note, acidic conditions could be avoided in high temperature tert-butyloxycarbonyl (Boc) deprotections. ${ }^{63}$

Highly corrosive reagents may not be suitable for a standard flow chemistry equipment and require special handling techniques and construction materials, such as a specialized dry zone for handling anhydrous $\mathrm{HCl}$ gas. ${ }^{39,64}$ In course of the flow syntheses of Ibuprofen (Fig. 12), corrosion of the back pressure regulator (BPR) unit was avoided by careful quenching of the $\mathrm{ICl}$ reagent. ${ }^{21}$ Hazardous leaks were encountered during an earlier study regarding the same API, which could be avoided by using high performance polymeric materials, which are resistant towards triflic acid. $^{20}$

Clogging (apart from the choice of solvent) can be prevented by careful choice of reagents (Fig. 13). Addition of trimethylsilyl trifluoromethanesulfonate (TMSOTf) as Lewis acid helped to avoid the formation of a precipitate in the hydrazone formation step in the synthesis of the biaryl unit of Atazanavir. ${ }^{65}$ Replacing the $i \mathrm{PrMgCl}$ reagent with its $\mathrm{LiCl}$ complex was useful in preventing clogging in the preparation of a $\delta$-opioid receptor agonist. ${ }^{66}$

More trivially, clogging can be hindered by employing wide bore channels or tubing, as well as applying agitation or sonic irradiation and controlling of fluid velocity. ${ }^{25,27,67}$ If clogging is caused by the crystallization of low melting substances, the heating of the problematic areas is an effective method. ${ }^{39}$ In the gas-liquid two phase flow during an ozonolysis leading to drug candidate 


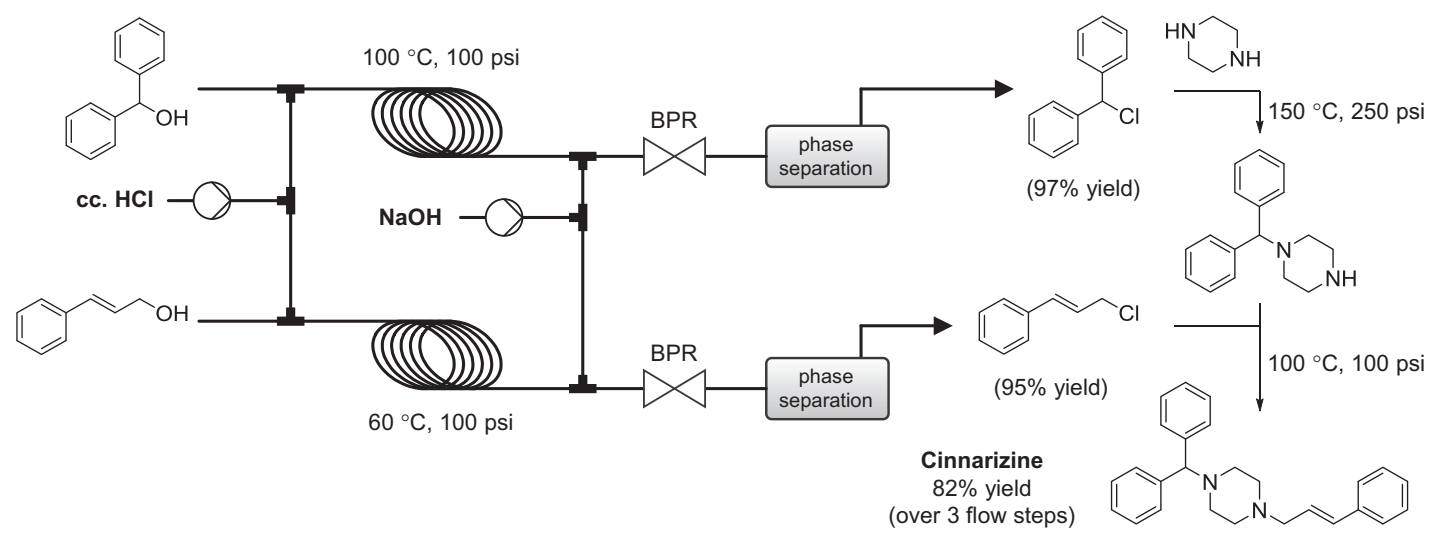

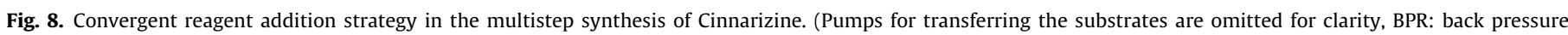
regulator.)

(a) Water soluble phenoxide intermediate

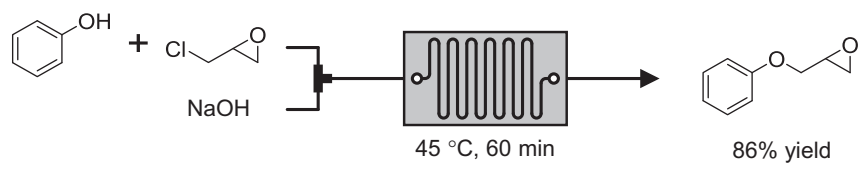

(b) Insoluble phenoxide intermediate

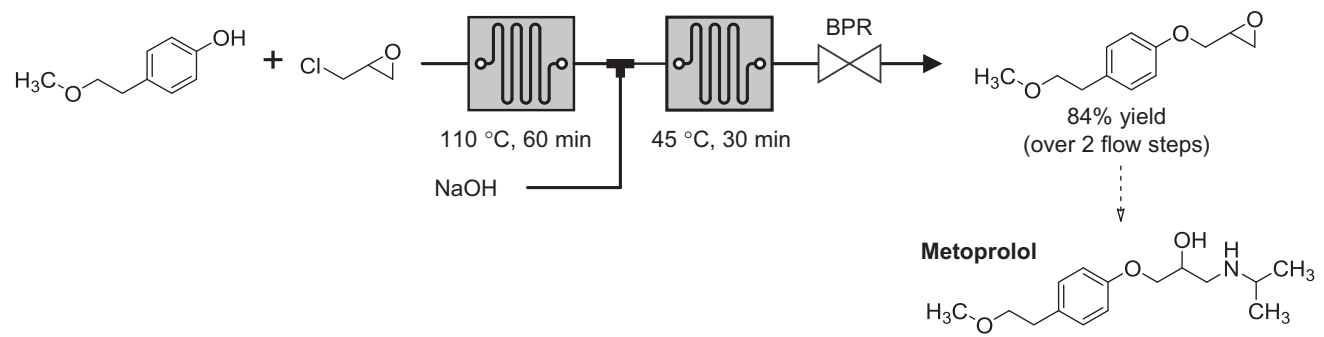

Fig. 9. Differentiation of flow paths according to the solubility of the intermediate. (Pumps are omitted for clarity, BPR: back pressure regulator.)

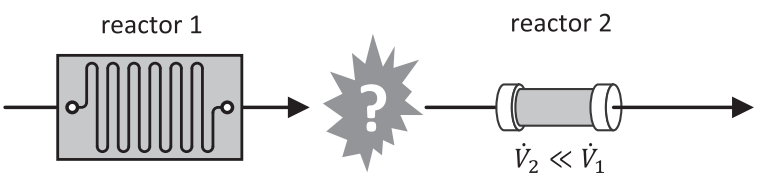

(a) Scale up of the limiting reactor

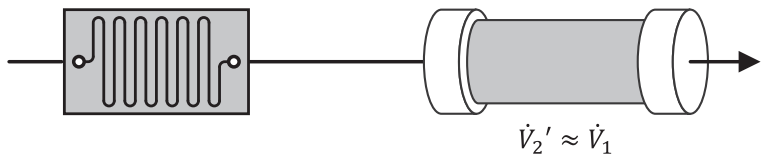

(b) Distribution of the main stream to even parts

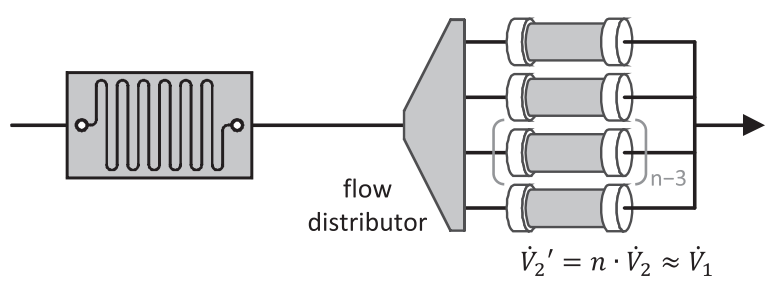

Fig. 10. Strategies for the uninterrupted connection of sequential flow reactors (or sub-processes) with different throughputs.

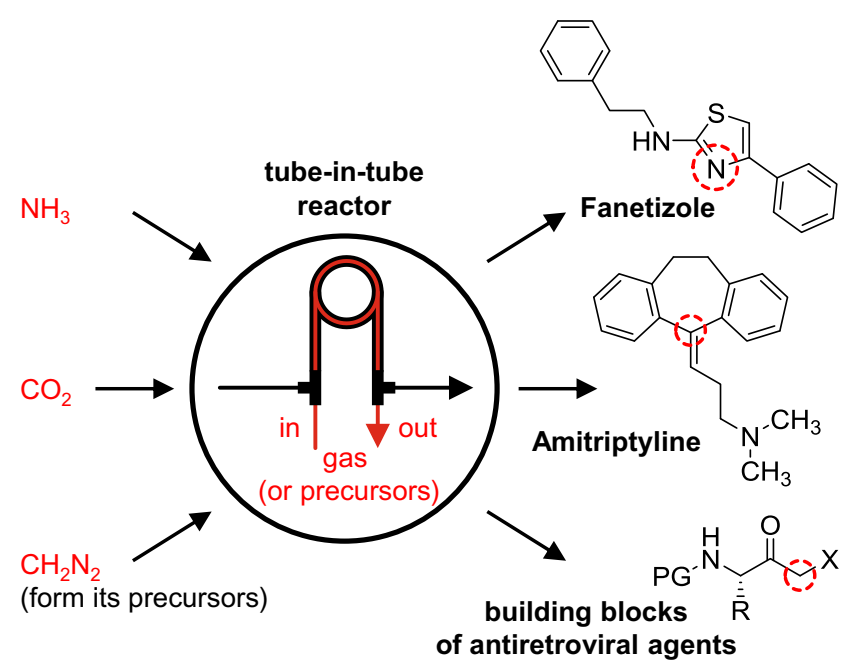

Fig. 11. Introduction of key structural elements into APIs using tube-in-tube reactors as part of multistep flow systems. (PG: protecting group, X: halogen atom). 
(a)

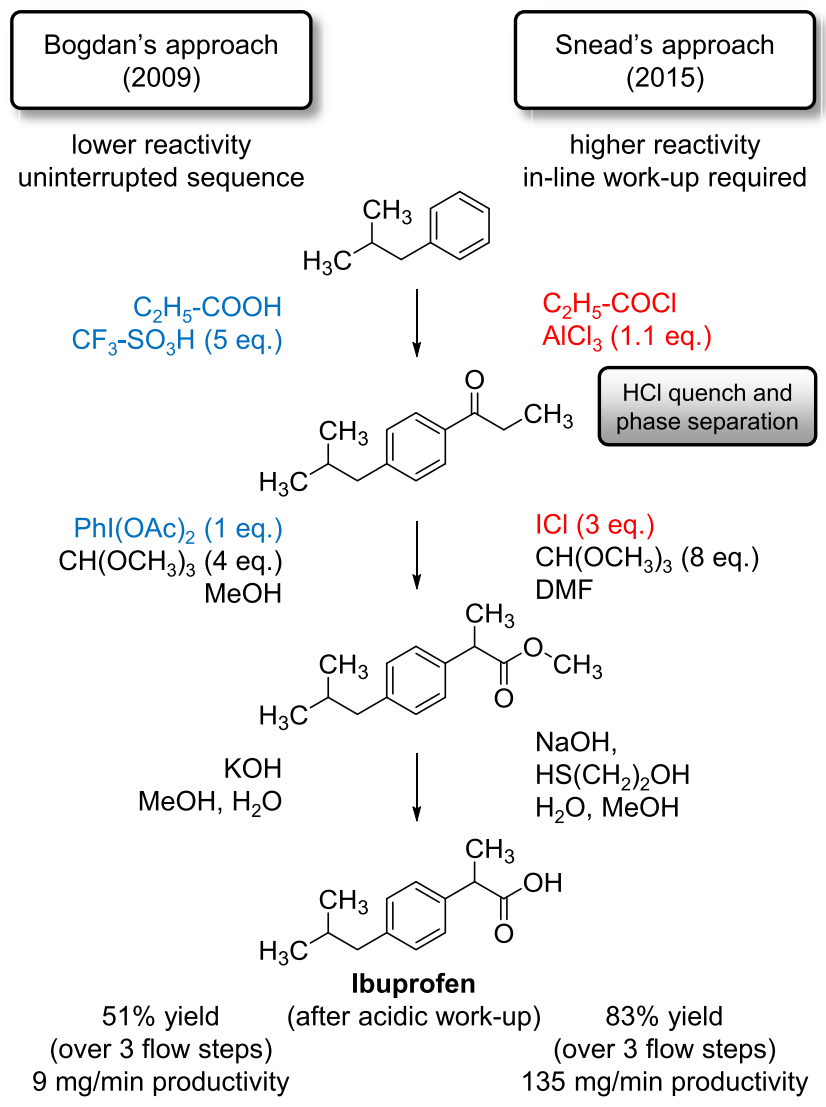

Fig. 12. Side-by-side comparison of two flow sequences to Ibuprofen.

OZ439, the evaporation of the liquid phase caused clogging. Overcoming this issue was possible by dilution, while flow rate was increased in order to maintain the same level of throughput. ${ }^{68}$

\subsection{Stability of packed columns}

Innovative practical solutions can ensure the long term operation of packed columns, which is required for production scale processes.

The synthesis of both enantiomers of Rolipram was realized in a pioneering sequence consisting only of solid catalytic packed bed reactors. In order to achieve continuous, stable operation for longer periods of time, the catalysts were packed together with solid additives. Elaborately placed pre-columns were also introduced to the system..$^{69,33}$

In a key reduction step leading to artemisinin-derived medicines, a mixture of solid $\mathrm{NaBH}_{4}$ and Celite ${ }^{\circledR}$ proved to be effective.
Still, $\mathrm{LiCl}$ and $\mathrm{Li}_{2} \mathrm{CO}_{3}$ additives had to be added to the reactant bed, to prevent pressure fluctuations. ${ }^{57}$

Modification of the processing parameters may also be necessary, when long term operation is desired. The opening Knoevenagel addition step of the synthesis of a Nevirapine precursor could be efficiently conducted on a solid basic $\mathrm{Al}_{2} \mathrm{O}_{3}$. However, the absorption of the water formed during the reaction limited the longevity of the catalyst. Increasing temperature and diluting the reaction mixture proved to be beneficial for stability. ${ }^{70}$

\subsection{Self-controlling systems and automation}

The inherent instability of these increased complexity systems can be mitigated using built-in control mechanisms and automation that are available for multistep flow systems. ${ }^{27,71}$ Such approaches have been implemented on a system level in API syntheses. $^{23-25}$

\section{Analytical methods}

\subsection{Possibilities and limitations}

Continuous flow processing allows convenient in situ analysis of reaction mixtures, by in-line (the entire stream is passed through the measuring cell) or on-line (representative aliquots are analyzed) techniques. ${ }^{7,72,73}$ Several different analytical systems were used successfully, such as in-line FT-IR (predominantly with Attenuated Total Reflectance (ATR) cells), ${ }^{74-80} \mathrm{NIR}^{81,82} \operatorname{Raman}^{83}$ and NMR spectroscopy, ${ }^{84,85}$ as well as on-line MS ${ }^{86,87}$ and HPLC. ${ }^{88,89}$

However, everyday application of these approaches is hindered by the fact that off-line solutions are usually more convenient, since a wider toolbox (consisting of existing equipment) is available for the analysis of less demanding analytes (i.e. less complicated matrix, solvent and concentration can be freely chosen). Additionally, they don't require difficult to implement sampling, continuous dilution/concentration and automation procedures.

\subsection{Successful applications}

Nevertheless, in-line or on-line analysis provides significant benefits for multistep flow processing in the following situations.

In-line sensors can inform the operator about the location and concentration of the reactants along the flow path, in order to allow precise timing and addition of reagents in the downstream transformations, which is extremely useful when working with limited quantities. ${ }^{66,90}$

Instable, short-lived intermediates, such as highly reactive acyl azide $^{75}$ and diazonium ${ }^{86}$ species, as well as the Vilsmeier-Haack reagent, ${ }^{91}$ can be directly studied in situ using IR spectroscopic or mass spectrometric methods (Fig. 14). This approach provides

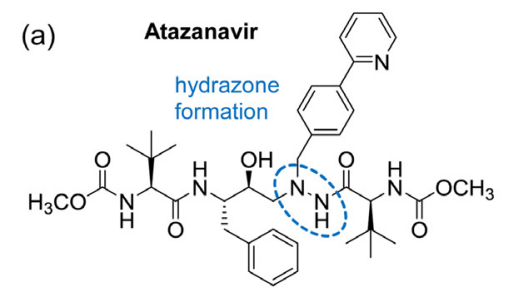

source of clogging:

precipitation of salts

solution:

application of TMSOTf as Lewis acid (b)

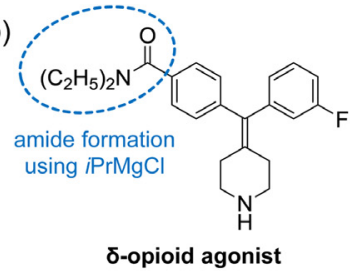

source of clogging:

precipitation of magnesium salts solution:

application of $\mathrm{iPrgCl} \cdot \mathrm{LiCl}$ complex (c)

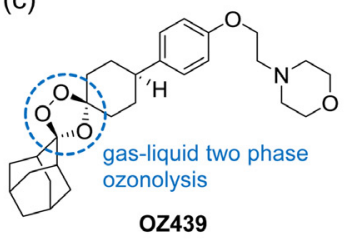

source of clogging:

evaporation of the liquid phase solution:

dilution and higher flow rate

Fig. 13. Strategies for the prevention of clogging in flow steps for introducing key structural elements towards Atazanavir (a), $\delta$-opioid agonist (b), and OZ439 (c). 
<smiles>[R]C([NH])=O</smiles><smiles>O=C([O-])c1ccccc1[N+](=O)[O-]</smiles>

acyl azides

FT-IR

$1711 \mathrm{~cm}^{-1}$

\section{diazonium ion ESI-MS $\mathrm{m} / \mathrm{z} 149$}

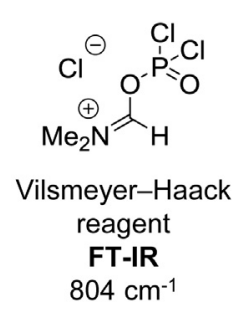

Fig. 14. Selected examples of in situ analysis of reactive intermediates encountered in continuous flow synthesis.

insight into the reaction mechanism and enables more informed optimization studies.

Automated self-optimization can be achieved by using feedback from the output to the control the pumps and heating units, aided by elaborate computer algorithms and DoE (Design of Experiments) statistical design. ${ }^{78,87-89,92-94}$

Realization of production scale API synthesis cannot be imagined without strict control of processes and final product quality. ${ }^{25}$ These efforts are exemplified by the production of Artemisinin related APIs, where monitoring of the reaction stream after a photochemical transformation could reveal an eventual lamp failure. ${ }^{57}$

\section{Purification in flow}

Flow synthesis is usually followed by discontinuous purification, because the number of available continuous solutions is limited. ${ }^{95}$ The existing methods $\mathrm{s}^{7,73}$ can be classified as in-line work-up or final product purification techniques, according to the position in a multistep sequence, where they are preferably used.

\subsection{In-line work-up}

Most of the in-line work-up steps aim to remove the co-products, which are formed from the reagent in the course of the planned process. ${ }^{6}$ These impurities should not be confused by the by-products, which are structurally related to the desired product, but their formation is the consequence of undesired side reactions. In-line work-up can be achieved by filtration of solid co-products, liquid-liquid phase separation, gas-liquid phase separation or through the use of solid phase supported scavengers.

Filtration can only be categorized as a truly continuous in-line purification method (Fig. 15), when the product remains in the mother liquor, while the solid impurities are retained on the filter material (and then discarded by an appropriate mechanism). ${ }^{27}$

There are several examples of extraction methods using liquidliquid phase separation ${ }^{96,97}$ to eliminate the excess of the reagents, ${ }^{21,65}$ co-products, ${ }^{65}$ traces of solvents ${ }^{39,80}$ or cosolvents, ${ }^{29}$ which have been used in a previous step. Complete removal of water may require a column filled with solid $\mathrm{MgSO}_{4}$ desiccant after the phase separation, as exemplified in the flow preparation of

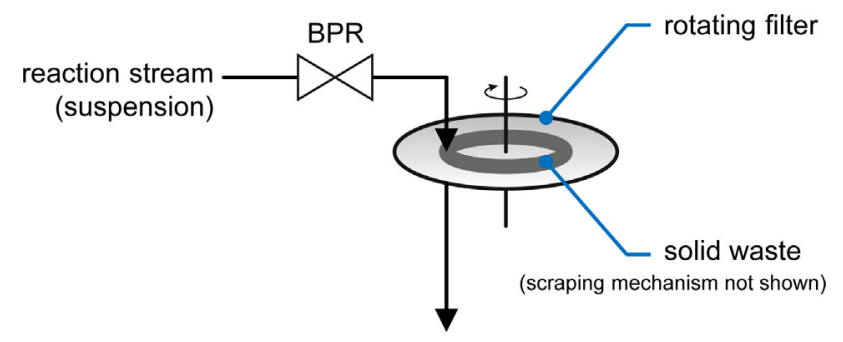

product solution

Fig. 15. In-line work-up by filtration of solid co-products (BPR: back pressure regulator).
Milnacipran analogs. ${ }^{80}$ The robust nature of liquid-liquid phase separation allows removal of multiple impurities at the same time. ${ }^{25,28,29,39,98}$

Insoluble gases cause irreproducible residence time (due to the expansion of bubbles) and potential side reactions in downstream steps. Excess of gaseous reagents or co-products can be removed conveniently by using gas-liquid phase separation units. Hydrogen is commonly used in flow synthesis, ${ }^{99,100}$ usually in excess amounts. When hydrogenation is followed by other steps, ${ }^{9,26,29,33,101,102}$ a simple buffer flask allows the outgassing of hydrogen, after the pressure is reduced. However, in some cases the applied chemistry did not tolerate this method. Semipermeable Teflon ${ }^{\circledR}$ AF2400 membrane (Fig. 16) was used to remove excess of diazomethane as well as the formed nitrogen. ${ }^{103}$ A similar set-up was employed to eliminate excess $\mathrm{CO}_{2}$ in the lithiation sequence leading to the core of Amitriptyline. ${ }^{48}$

Columns filled with solid phase supported scavenger resins are widely used for purification of the stream..$^{70,104}$ The combination of multiple, differently functionalized scavenger resins is a common practice for the removal of several different impurities. ${ }^{44,66,33,102,105-107}$ In an illustrative example, removal of homogeneous transition metal complexes was possible this way (Fig. 17), which prevented harmful catalytic activity in downstream heterogeneous nitro group reductions in the flow synthesis of the fungicide Boscalid ${ }^{\circledR} .{ }^{104} \mathrm{~A}$ similar concept was applied in the early steps towards Olanzapine. ${ }^{28}$ The drawbacks of this method are the wide dispersion of reactants on the column ${ }^{90}$ and the exhaustion of the resin by time, principally when the stoichiometric amounts of the immobilized reagent is consumed. These issues can be solved by engineering solutions, such as intelligent pumping $^{90}$ and switching between multiple columns. ${ }^{108}$

With this knowledge at hand, multistep processes can be designed to facilitate the purification procedure between the reaction steps, which was demonstrated in the process leading to Efavirenz (Fig. 18). The appropriate choice of the trifluoroacetylation reagent allowed easy removal of the co-product by a simple scavenging column. ${ }^{109}$

\subsection{Final product purification}

After the final synthetic step, the API has to be purified to meet the standards of regulatory agencies. The hitherto discussed separation techniques, which could be ideally used between intermediate steps, are not adequate for this goal by themselves.

Continuous crystallization was employed in case of Rufinamide $^{22}$ and Aliskiren, ${ }^{23,24}$ while semi-batch recrystallization of the crude products was necessary to provide pure Diphenhydramine, $^{25}$ Fluoxetine $^{25}$ and Lidocaine. ${ }^{25,110}$ A salt formation - neutralization sequence using multiple extraction steps, followed by precipitation and recrystallization yielded highly pure Diazepam. ${ }^{25}$ 


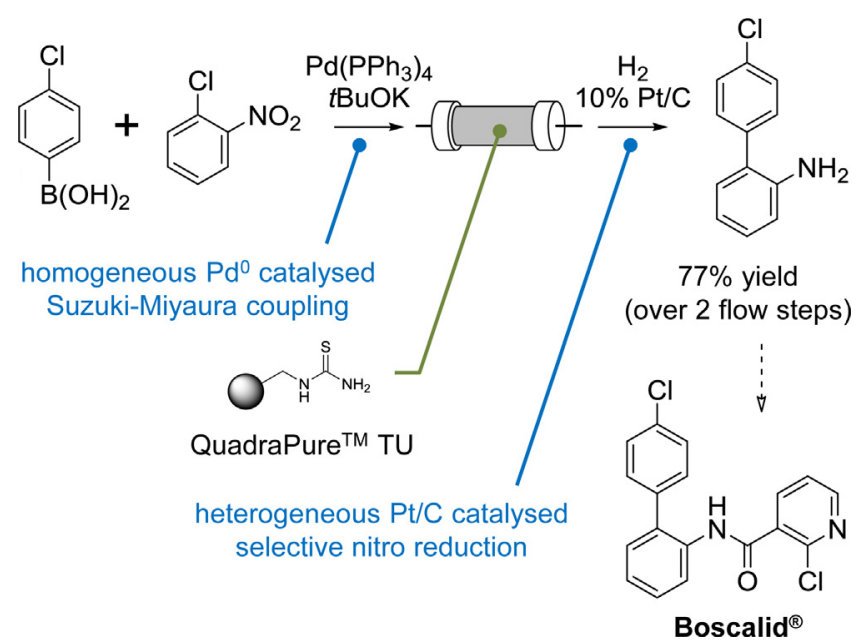

Fig. 17. Application of polymer bound thiourea (QuadraPure ${ }^{\mathrm{TM}} \mathrm{TU}$ ) scavenger resin to remove homogeneous transition metal catalyst before the next catalytic step in the flow synthesis of Boscalid ${ }^{\circledR}$.

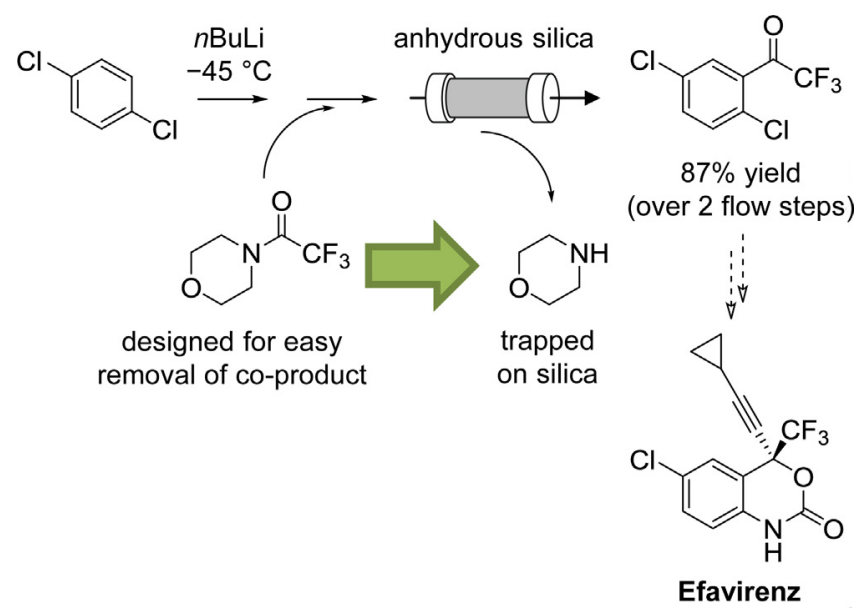

Fig. 18. Design of the flow chemical synthetic procedure towards Efavirenz, which facilitates in-line purification.

Catch and release chromatography ${ }^{26}$ enables stepwise introduction of a continuous stream of the reaction mixture to a single bed of stationary phase, followed by elution of the product. High purity can be achieved, as it was demonstrated in case of Iloperidone $^{36}$ and Flurbiprofen. ${ }^{111,112}$ However, the capacity of the employed stationary phase determines the amount of the adsorbed product during the "catch" phase and thus limits the achievable throughput.

The complexity of artemisinin-derived medicinal compounds call for sophisticated systems consisting of the combination of in-line work-up and multiple final purification techniques. A continuous three-stage purification method was developed for $\alpha$-artesunate, consisting of precipitation and filtration of by-products, followed by chromatography in a multi-column arrangement and finally crystallization of the product. ${ }^{57}$ In a more recent study, a closely related system was constructed, based on continuously operated simulated moving bed (SMB) chromatography (Fig. 19). ${ }^{113,114}$ Following the synthesis of Artemisinin, first an SMB chromatographic separation brought the product mixture to 92\% purity, then crystallization from the concentrated mixture provided the pure API in $99.9 \%$ purity. ${ }^{115}$

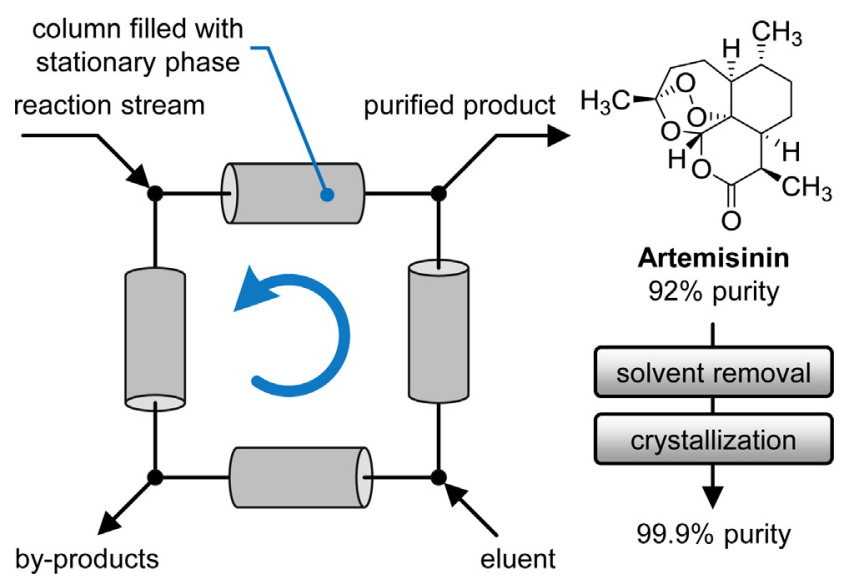

Fig. 19. General scheme of a continuously operated simulated moving bed (SMB) chromatography system integrated with crystallization for the purification of Artemisinin following its continuous flow synthesis. The circular arrow marks the simulated counterclockwise movement of the bed (this is achieved by clockwise switching of the inlet and outlet ports).

\section{Conclusions}

The chemical knowledge and technology for the realization of multistep flow synthesis (and the following analysis and purification) exists, but connecting individual chemical steps holds hidden traps. We summarized the innovative solutions for these challenges, in order to benefit chemists aiming to build such systems for the synthesis of APIs.

The applied synthetic methods must overcome restrictions (solubility, reagent compatibility, feasibility). Still, prior design of the complete process helps to exploit the benefits of flow methodology. In-line or on-line analysis of reaction mixtures is well suited for flow processing, but their real value can only be exploited for some well-designed, special applications. The utility of the available continuous purification methods can be maximized by proper design of the synthetic process.

The advancement of flow chemistry instrumentation is impressive, and we foresee modular, customizable equipment that allow control of the whole system through extensive standardization and intercompatibility of the units. This would enable quick assembly of lab-scale systems, which could be advanced for continuous API production in the near future.

\section{Acknowledgments}

The work of P.B. and R.Ö. was funded by the Gedeon Richter Talentum Foundation; R.Ö. also thanks the Pro Progressio Foundation for financial support.

\section{References}

1. Brennan Z. FDA Calls on Manufacturers to Begin Switch from Batch to Continuous Production; 2015. <http://www.in-pharmatechnologist.com/Processing/ FDA-calls-on-manufacturers-to-begin-switch-from-batch-to-continuousproduction> Accessed September 4th 2016

2. Yu L. Continuous Manufacturing Has a Strong Impact on Drug Quality; 2016. <http://blogs.fda.gov/fdavoice/index.php/2016/04/continuous-

manufacturing-has-a-strong-impact-on-drug-quality> Accessed September 4th 2016.

3. Schaber SD, Gerogiorgis DI, Ramachandran R, Evans JMB, Barton PI, Trout BL. Ind Eng Chem Res. 2011:50:10083-10092.

4. Jolliffe HG, Gerogiorgis DI. Chem Eng Res Des. 2015;97:175-191.

5. Stanton D. Lack of Talent will Hamper Continuous Manufacturing Adoption, Says MIT Prof.; 2015. <http://www.in-pharmatechnologist.com/Processing/Lack-oftalent-will-hamper-continuous-manufacturing-uptake-MIT-Prof $>$ Accessed September 4th 2016

6. Kobayashi S. Chem Asian J. 2016;11:425-436. 
7. Ley SV, Fitzpatrick DE, Ingham RJ, Myers RM. Angew Chem Int Ed. 2015:54:3449-3464.

8. Ley SV, Fitzpatrick DE, Myers RM, Battilocchio C, Ingham RJ. Angew Chem Int Ed. 2015;54:10122-10136.

9. Lövei K, Greiner I, Éles J, et al. J Flow Chem. 2015;5:74-81.

10. Webb D, Jamison TF. Chem Sci. 2010;1:675-680.

11. Wegner J, Ceylan S, Kirschning A. Chem Commun. 2011;47:4583-4892.

12. Wegner J, Ceylan S, Kirschning A. Adv Synth Catal. 2012;354:17-57.

13. Malet-Sanz L, Susanne F. J Med Chem. 2012:55:4062-4098.

14. Gutmann B, Cantillo D, Kappe CO. Angew Chem Int Ed. 2015;54:6688-6728.

15. Badman C, Trout BL. J Pharm Sci. 2015;104:779-780.

16. Baxendale IR, Braatz RD, Hodnett BK, et al. J Pharm Sci. 2015:104:781-791.

17. Byrn S, Futran M, Thomas H, et al. J Pharm Sci. 2015;104:792-802.

18. Rossetti I, Compagnoni M. Chem Eng J. 2016;296:56-70.

19. Yang JC, Niu D, Karsten BP, Lima F, Buchwald SL. Angew Chem Int Ed. 2016:55:2531-2535.

20. Bogdan AR, Poe SL, Kubis DC, Broadwater SJ, McQuade DT. Angew Chem Int Ed. 2009;48:8547-8550.

21. Snead DR, Jamison TF. Angew Chem Int Ed. 2015;54:983-987.

22. Borukhova S, Noël T, Metten B, de Vos E, Hessel V. ChemSusChem. 2013;6:2220-2225.

23. Mascia S, Heider PL, Zhang H, et al. Angew Chem Int Ed. 2013;52:12359-12363.

24. Heider PL, Born SC, Basak S, et al. Org Process Res Dev. 2014;18:402-409.

25. Adamo A, Beingessner RL, Behnam M, et al. Science. 2016;352:61-67.

26. Baxendale IR, Deeley J, Griffiths-Jones CM, Ley SV, Saaby S, Tranmer GK. Chem Commun. 2006;2566-2568.

27. Ingham RJ, Battilocchio C, Fitzpatrick DE, Sliwinski E, Hawkins JM, Ley SV Angew Chem Int Ed. 2015;54:144-148.

28. Hartwig J, Ceylan S, Kupracz L, Coutable L, Kirschning A. Angew Chem Int Ed. $2013 \cdot 52 \cdot 9813-9817$.

29. Ghislieri D, Gilmore K, Seeberger PH. Angew Chem Int Ed. 2015;54:678-682.

30. Martin AD, Siamaki AR, Belecki K, Gupton BF. J Flow Chem. 2015;5:145-147.

31. Zhang P, Russell MG, Jamison TF. Org Process Res Dev. 2014;18:1567-1570.

32. Herath A, Dahl R, Cosford NDP. Org Lett. 2010;12:412-415.

33. Tsubogo T, Oyamada H, Kobayashi S. Nature. 2015;520:329-332.

34. Soldi L, Ferstl W, Loebbecke S, et al. J Catal. 2008;258:289-295.

35. Ishitani H, Saito Y, Tsubogo T, Kobayashi S. Org Lett. 2016:18:1346-1349.

36. Hartwig J, Kirschning A. Chem Eur J. 2016;22:3044-3052.

37. May SA, Johnson MD, Braden TM, et al. Org Process Res Dev. 2012;16:982-1002.

38. Carneiro PF, Gutmann B, de Souza ROMA, Kappe CO. ACS Sustain Chem Eng. 2015;3:3445-3453.

39. Borukhova S, Noël T, Hessel V. ChemSusChem. 2016;9:67-74.

40. Nobuta T, Xiao G, Ghislieri D, Gilmore K, Seeberger PH. Chem Commun. 2015;51:15133-15136.

41. Nagaki A, Kim H, Usutani H, Matsuo C, Yoshida J. Org Biomol Chem. 2010;8:1212-1217.

42. Nagaki A, Hirose K, Tonomura O, et al. Org Process Res Dev. 2016;20:687-691.

43. Fekete M, Glasnov T. In: Darvas F, Hessel V, Dormán G, editors. Flow Chemistry: Fundamentals, Vol. 1. Berlin: de Gruyter; 2014:95-140.

44. Nakano Y, Savage GP, Saubern S, Scammells PJ, Polyzos A. Aust J Chem. 2013;66:178-182.

45. Polyzos A, O’Brien M, Petersen TP, Baxendale IR, Ley SV. Angew Chem Int Ed. 2011;50:1190-1193.

46. O'Brien M, Taylor N, Polyzos A, Baxendale IR, Ley SV. Chem Sci. $2011 ; 2: 1250-1257$.

47. Pastre JC, Browne DL, O’Brien M, Ley SV. Org Process Res Dev. 2013:17:1183-1191.

48. Kupracz L, Kirschning A. Adv Synth Catal. 2013;355:3375-3380.

49. Pinho VD, Gutmann B, Miranda LSM, de Souza ROMA, Kappe CO. J Org Chem. 2014;79:1555-1562.

50. Knowles JP, Elliott LD, Booker-Milburn KI. Beilstein J Org Chem. 2012;8:2025-2052.

51. Su Y, Straathof NJW, Hessel V, Noël T. Chem Eur J. 2014;20:10562-10589.

52. Gilmore K, Seeberger PH. Chem Rec. 2014:14:410-418.

53. Cambié D, Bottecchia C, Straathof NJW, Hessel V, Noël T. Chem Rev. 2016;116:10276-10341.

54. Watts K, Baker A, Wirth T. J Flow Chem. 2014;4:2-11.

55. Lévesque F, Seeberger PH. Angew Chem Int Ed. 2012;51:1706-1709.

56. Kopetzki D, Lévesque F, Seeberger PH. Chem Eur J. 2013;19:5450-5456.

57. Gilmore K, Kopetzki D, Lee JW, et al. Chem Commun. 2014;50:12652-12655.

58. Baumann M, Baxendale IR. React Chem Eng. 2016;1:147-150.

59. Kabeshov MA, Musio B, Murray PRD, Browne DL, Ley SV. Org Lett. 2014;16:4618-4621.

60. Stalder R, Roth GP. ACS Med Chem Lett. 2013;4:1119-1123.

61. Hopkin MD, Baxendale IR, Ley SV. Chem Commun. 2010;46:2450-2452.

62. Hopkin MD, Baxendale IR, Ley SV. Org Biomol Chem. 2013;11:1822-1839.

63. Bogdan AR, Charaschanya M, Dombrowski AW, Wang Y, Djuric SW. Org Lett. 2016:18:1732-1735.

64. Borukhova S, Noël T, Hessel V. Org Process Res Dev. 2016;20:568-573.
65. Dalla-Vechia L, Reichart B, Glasnov T, Miranda LSM, Kappe CO, de Souza ROMA. Org Biomol Chem. 2013:11:6806-6813.

66. Qian Z, Baxendale IR, Ley SV. Chem Eur J. 2010;16:12342-12348.

67. Hartman RL, Naber JR, Zaborenko N, Buchwald SL, Jensen KF. Org Process Res Dev. 2010;14:1347-1357.

68. Lau S-H, Galván A, Merchant RR, et al. Org Lett. 2015;17:3218-3221.

69. Tsubogo T, Yamashita Y, Kobayashi S. Chem Eur J. 2012;18:13624-13628.

70. Longstreet AR, Opalka SM, Campbell BS, Gupton BF, McQuade DT. Beilstein J Org Chem. 2013:9:2570-2578.

71. Fitzpatrick DE, Battilocchio C, Ley SV. ACS Cent Sci. 2016;2:131-138.

72. McMullen JP, Jensen KF. Annu Rev Anal Chem. 2010;3:19-42.

73. Darvas F, Dormán G, Fekete M. In: Darvas F, Hessel V, Dormán G, editors. Flow Chemistry: Applications, Vol. 2. Berlin: de Gruyter; 2014:213-252.

74. Hübner S, Bentrup U, Budde U, et al. Org Process Res Dev. 2009;13:952-960.

75. Carter CF, Lange H, Ley SV, et al. Org Process Res Dev. 2010;14:393-404.

76. Smith CJ, Nikbin N, Ley SV, Lange H, Baxendale IR. Org Biomol Chem. 2011;9:1938-1947.

77. Brodmann T, Koos P, Metzger A, Knochel P, Ley SV. Org Process Res Dev. 2012:16:1102-1113.

78. Moore JS, Jensen KF. Org Process Res Dev. 2012;16:1409-1415.

79. Müller STR, Murat A, Maillos D, Lesimple P, Hellier P, Wirth T. Chem Eur J 2015;21:7016-7020.

80. Müller STR, Murat A, Hellier P, Wirth T. Org Process Res Dev. 2016;20:495-502.

81. Cervera-Padrell AE, Nielsen JP, Jønch Pedersen M, et al. Org Process Res Dev. 2012;16:901-914.

82. Mitic A, Cervera-Padrell AE, Mortensen AR, et al. Org Process Res Dev. 2016;20:395-402.

83. Hamlin TA, Leadbeater NE. Beilstein J Org Chem. 2013;9:1843-1852.

84. Bart J, Kolkman AJ, Oosthoek-de Vries AJ, et al. J Am Chem Soc. 2009:131:5014-5015.

85. Goldbach M, Danieli E, Perlo J, et al. Tetrahedron Lett. 2016;57:122-125.

86. Browne DL, Wright S, Deadman BJ, et al. Rapid Commun Mass Spectrom 2012;26:1999-2010.

87. Holmes N, Akien GR, Savage RJD, et al. React Chem Eng. 2016;1:96-100.

88. McMullen JP, Jensen KF. Org Process Res Dev. 2010;14:1169-1176.

89. McMullen JP, Stone MT, Buchwald SL, Jensen KF. Angew Chem Int Ed. 2010:49:7076-7080.

90. Lange H, Carter CF, Hopkin MD, et al. Chem Sci. 2011;2:765-769.

91. van den Broek SAMW, Leliveld JR, Becker R, et al. Org Process Res Dev. 2012;16:934-938.

92. Rasheed M, Wirth T. Angew Chem Int Ed. 2011:50:357-358.

93. Holmes N, Akien GR, Blacker AJ, Woodward RL, Meadows RE, Bourne RA. React Chem Eng. 2016;1:366-371.

94. Mohamed DKB, Yu X, Li J, Wu J. Tetrahedron Lett. 2016;57:3965-3977.

95. Agostino FJ, Krylov SN. TrAC, Trends Anal Chem. 2015;72:68-79.

96. Cervera-Padrell AE, Morthensen ST, Lewandowski DJ, Skovby T, Kiil S, Gernaey KV. Org Process Res Dev. 2012;16:888-900.

97. Adamo A, Heider PL, Weeranoppanant N, Jensen KF. Ind Eng Chem Res. 2013;52:10802-10808.

98. Hu DX, O’Brien M, Ley SV. Org Lett. 2012;14:4246-4249.

99. Irfan M, Glasnov TN, Kappe CO. ChemSusChem. 2011;4:300-316.

100. Cossar PJ, Hizartzidis L, Simone MI, McCluskey A, Gordon CP. Org Biomol Chem. 2015;13:7119-7130.

101. Brasholz M, Macdonald JMJ, Saubern S, Ryan JH, Holmes AB. Chem Eur J. 2010;16:11471-11480.

102. Petersen TP, Mirsharghi S, Rummel PC, et al. Chem Eur J. 2013;19:9343-9350.

103. Pinho VD, Gutmann B, Kappe CO. RSC Adv. 2014;4:37419-37422.

104. Glasnov TN, Kappe CO. Adv Synth Catal. 2010;352:3089-3097.

105. Carter CF, Baxendale IR, Pavey JBJ, Ley SV. Org Biomol Chem. 2010;8:1588-1595.

106. Baumann M, Baxendale IR, Brasholz M, Hayward JJ, Ley SV, Nikbin N. Synlett. 2011;1375-1380.

107. Baxendale IR, Hornung C, Ley SV, Molina J de MM, Wikström A. Aust J Chem 2013;66:131-144.

108. Zak J, Ron D, Riva E, Harding HP, Cross BCS, Baxendale IR. Chem Eur J. 2012;18:9901-9910.

109. Correia CA, Gilmore K, McQuade DT, Seeberger PH. Angew Chem Int Ed 2015;54:4945-4948.

110. Monbaliu J-CM, Stelzer T, Revalor E, Weeranoppanant N, Jensen KF, Myerson AS. Org Process Res Dev. 2016;20:1347-1353.

111. Tamborini L, Romano D, Pinto A, Bertolani A, Molinari F, Conti P. J Mol Catal B Enzym. 2012;84:78-82.

112. Tamborini L, Romano D, Pinto A, et al. Tetrahedron Lett. 2013;54:6090-6093.

113. O’Brien AG, Horváth Z, Lévesque F, Lee JW, Seidel-Morgenstern A, Seeberger PH. Angew Chem Int Ed. 2012;51:7028-7030.

114. Lee JW, Horváth Z, O'Brien AG, Seeberger PH, Seidel-Morgenstern A. Chem Eng J. 2014;251:355-370.

115. Horváth Z, Horosanskaia E, Lee JW, et al. Org Process Res Dev. 2015;19:624-634. 